\title{
Effect of mammary stimulation on dairy cows and heifers exposed to a lactation induction protocol
}

\author{
Reeza Ramgattie $^{1^{*}}$, Narendra Siew ${ }^{1}$, Michael Diptee ${ }^{2}$, Valerie Stoute $^{1}$, Marlon Knights ${ }^{3}$ \\ ${ }^{1}$ University of Trinidad \& Tobago, Trinidad, West-Indies; ${ }^{*}$ Corresponding Author: reeza.ramgattie@gmail.com \\ ${ }^{2}$ University of the West Indies, School of Veterinary Medicine, Trinidad, West-Indies \\ ${ }^{3}$ Division of Animal \& Nutritional Sciences, DCANRD, West Virginia University, Morgantown, USA
}

Received 5 November 2013; revised 12 December 2013; accepted 27 December 2013

Copyright (C) 2014 Reeza Ramgattie et al. This is an open access article distributed under the Creative Commons Attribution License, which permits unrestricted use, distribution, and reproduction in any medium, provided the original work is properly cited. In accordance of the Creative Commons Attribution License all Copyrights (C) 2014 are reserved for SCIRP and the owner of the intellectual property Reeza Ramgattie et al. All Copyright (C) 2014 are guarded by law and by SCIRP as a guardian.

\section{ABSTRACT}

Cows $(n=21)$, dried off for a minimum of 45 days, and nulliparous heifers $(n=26)$, at ages > 18 months old, were placed on a 12-day Lactation Induction (LI) protocol. One group of animals (including both cows and heifers) received 3-minute mammary gland stimulation, along with the LI protocol. Another group, again including both cows and heifers, received no stimulation. Only the LI protocol consisted of two injections of prostaglandin F2a (PGF2a; 25 mg) 11 days apart, followed by subcutaneous injections of $17 ß$-estradiol $(0.1 \mathrm{mg} / \mathrm{kg} \mathrm{BW} / \mathrm{d})$ and progesterone $(0.25 \mathrm{mg} / \mathrm{kg}$ BW/d) beginning 1 day later and continuing for seven (7) days. After this step, all animals received another injection of PGF2 $\alpha$ on day 8, followed by intramuscular injections of reserpine $(5 \mathrm{mg} / \mathrm{d})$ and dexamethasone $(20 \mathrm{mg} / \mathrm{d})$ on each of days 9 to 12 . All animals were milked, beginning on day 13 , for a period of 154 days. For all animals, the success rate for lactation induction was $78 \% \pm 6.3 \%$ and the mean weekly milk yield was $78.2 \mathrm{~kg}$. Neither value was affected by mammary stimulation. Parity did not significantly impact on the success rate, but it did affect the mean weekly milk yield. Milk yield varied significantly $(p<0.001)$ with week, peaking during week 9. Peak milk production and persistency were $101.6 \mathrm{~kg} \pm 5.9$ $\mathrm{kg}$ and 16.9 weeks \pm 2.4 weeks respectively, with neither being significantly ( $\alpha=0.05$ level) affected by stimulation or by parity. However, heifers (at 8.2 weeks \pm 1.0 week) tended $(p=0.1)$ to reach peak milk production earlier than cows (at 10.7 weeks \pm 1.3 ). The milk produced was sold at a net profit per animal treated of $\$ 2206.31$ TT. Hence, one can conclude that a Lactation Induction protocol can be a useful management tool to increase production and profitability of dairy operations in the tropics.

\section{KEYWORDS}

Mammary-Stimulation; Lactation-Induction; Cows; Heifers

\section{INTRODUCTION}

As the populations in developing countries continue to expand, the demand for milk and milk products continues to increase. Despite this growing demand, milk production and productivity of dairy animals have either remained constant or declined in many developing countries over the last two decades, resulting in a decrease in per capita milk production and rendering these countries more food insecure [1].

A major factor limiting productivity of dairy cattle in developing countries is poor reproductive performance. No pregnancies equate to no lactation and no milk yield. Measures of reproductive performance in dairy cattle in these countries are below acceptable standards in almost every category, and have not shown any signs of improving over the last 4 decades. Milk production is dependent on the hormonal milieu created during pregnancy, so failure to get a cow or heifer pregnant will result in a large proportion of females in the herd producing at low levels during an extended lactation or nonlactating (dry) period.

Poor reproductive performance represents a significant cost to the producer. It takes a 3 - 4 years period before the heifer produces any saleable product. During this 
period, significant cost is incurred in managing the replacement heifer, while no income is derived from this animal. Additionally, significant cost is incurred due to culling of high producing animals that fail to get rebred, due to the cost associated with treating potential reproductive issues and that associated with rebreeding poor performing animals. Poor reproductive performance also denies the producer of a calf that can be used to expand the herd, can be selected to improve the genetic composition of the herd, or can be sold to derive additional income.

Under traditional management schemes, cows that fail to conceive are culled and replaced with heifers. It has been reported that reproductive problems account for $47 \%$ of the cows culled from the dairy herd between the ages of 3 and $8 \mathrm{yr}$ [2]. A more recent report estimated this figure to be $26.7 \%$ [3]. Loeffler et al. noted that it is often the highest milk producers that are at the greatest risk of failing to conceive in a timely manner, therefore, culling such cows represents a loss of some of the most profitable cows in the herd [4]. Additionally, it requires 25 to 26 months and rearing costs of $\$ 1150$ US to $\$ 1350$ US to bring a single heifer into production [5].

Inducing lactation in healthy cows, with good genetic merit for milk production, but who have failed to conceive, may be an economically viable alternative. Net Present Value (NPV) calculations for induced cows versus replacement heifers showed that the NPV for induced cows was $\$ 520$ US greater than that for replacement heifers. [6,7]. Magliaro et al. reported a higher NPV for cows induced into lactation compared to that for first-lactation cows, even when milk prices and replacement costs of heifers were $20 \%$ higher or lower [8]. The authors noted that the $20 \%-60 \%$ higher NPV obtained for induced cows was a conservative estimate as their calculations did not include health-related costs associated with post-calving disorders and higher insemination costs associated with lower fertility observed in firstlactation cows. An improved method to induce nonpregnant cows into lactation could return to production valuable healthy cows that would otherwise be culled, decreasing at the same time the need for replacement heifers.

Attempts to induce lactation have resulted in variable success rates of $58 \%$ to $80 \%$ and milk yields of $50 \%$ to $106 \%$ that of natural lactation [9-11]. Several factors, including the extent of mammary development, may have a significant impact on the peak and persistency of the induced lactation, particularly in heifers. Hence, the objectives of the present study were to determine the effect on milk production, on the whole, in cows and heifers, hormonally induced into lactation; to compare the responses of cows and heifers to mammary stimulation; and to determine if these responses to stimulation are confounded by the teat volumes of the animals studied.

\section{MATERIALS\& METHODS}

\subsection{Materials}

This research was approved by the ethics committee of the University of Trinidad \& Tobago, BAFT Campus.

The $\mathrm{PGF}_{2 \alpha}$ Lutalyse was obtained from Pfizer, Pharmacia \& Upjohn Company, NY. The other hormones, $17 \beta$ - estradiol, progesterone, reserpine and dexamethasone, were obtained from Sigma Chemicals, USA. A stock solution of the hormone medium of $17 \beta$ - estradiol $\left(12.5 \mathrm{mg} \cdot \mathrm{mL}^{-1}\right)$ and progesterone $\left(31.25 \mathrm{mg} \cdot \mathrm{mL}^{-1}\right)$ in absolute ethanol was prepared for use in all the experiments. This solution was stored until needed in air tight containers at $4^{\circ} \mathrm{C}$.

\subsection{Farms and Animals}

The study was conducted during a period of twentyone (21) months on two dairy farms, The University of the West Indies Field Station, Mt. Hope and the Aripo Livestock Station located in North Central Trinidad $\left(10^{\circ} 40 \_\mathrm{N}, 61^{\circ} 31 \_\mathrm{W}\right)$.

The animals used in this study consisted of Holstein crossed with either Jersey or the Jamaica Hope breed. Cows $(\mathrm{N}=20)$ used in the study were dry for at least 45 days prior to the start of the study and had an average weight of $340 \mathrm{~kg}$, with an average body condition score of 3 to 3.5 ( 1 - 5 scale), using the Department for Environment, Food and Rural Affairs, DEFRA (2000) Condition Scoring of Dairy Cows. The milk yield of cows in both herds was 10 to $12 \mathrm{~kg}$ milk/animal/day. Heifers (N $=27$ ) were sexually mature (previously observed in heat), were at least eighteen (18) months old, and weighed more than $275 \mathrm{~kg}$. One heifer (\#247) was diagnosed with tick fever and subsequently died during the trial.

All animals were grazed on pasture consisting primarily of bamboo grass (Chasmanthium latifolium), pangola grass (Digitaria eriantha), tanner grass (Brachiaria radicans), kudzu (Pueraria lobata), elephant grass (Pennisetum purpureum) and mulato grass (Brachiaria spp. hybrids). A commercial $18 \%$ crude protein (CP) concentrate was fed to them at a rate of 3 or $4 \mathrm{~kg} /$ day for cows or heifers respectively for 23 days during the lactation induction protocol. During the 22 weeks of milk collection (177 days) ad libitum access to concentrate was provided to the animals twice per day, resulting in a total consumption per animal of approximately $5-6 \mathrm{~kg}$ per day.

\subsection{Lactation Induction Protocol}

All animals were treated with a lactation induction protocol as outlined in Figure 1. Animals received intramuscularly 2 doses of $\mathrm{PGF}_{2 \alpha}$ Lutalyse $(25 \mathrm{mg}), 10$ days apart, prior to initiation of hormonal therapy. A 


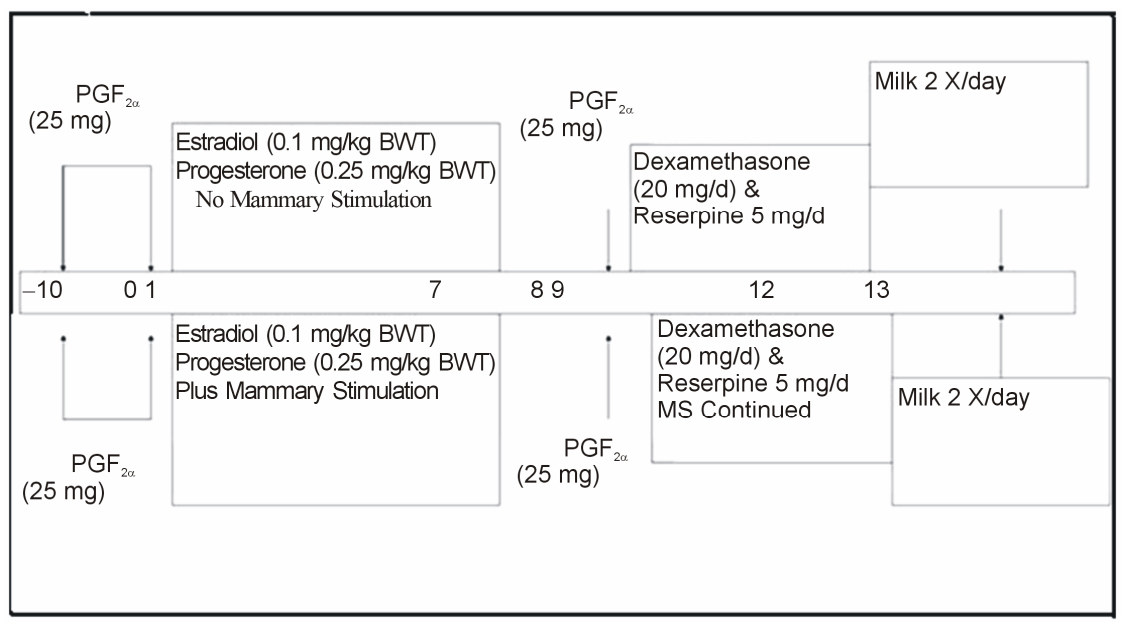

Figure 1. Lactation induction protocol and treatments.

common stock solution, containing $17 \beta$ - estradiol (12.5 $\left.\mathrm{mg} \cdot \mathrm{mL}^{-1}\right)$ and progesterone $\left(31.25 \mathrm{mg} \cdot \mathrm{mL}^{-1}\right)$, was administered subcutaneously each day from days 1 to 7 (where day 0 is the day of the second $\mathrm{PGF}_{2 \alpha}$ injection). The quantity of the stock solution required for an animal was based on its body weight $(0.1 \mathrm{mg}$ of $17 \beta$ - estradiol and $0.25 \mathrm{mg}$ of progesterone dispensed per $\mathrm{kg}$ body weight of the animal). On day 8 another injection of PGF $2 \alpha$ was given. Reserpine $\left(5 \mathrm{mg} \cdot \mathrm{day}^{-1}\right)$ and dexamethasone $\left(20 \mathrm{mg} \cdot \mathrm{day}^{-1}\right)$ were administered on days 9 to 12 via an intramuscular route.

\subsection{Treatments}

Both cows and heifers were randomly assigned to one of two treatments. Animals (cows and heifers) assigned to treatment 1 served as control animals and received no treatment beyond the lactation induction procedures. Animals (cows and heifers) in group 2 were subjected to mammary stimulation, during which the teats of the animals were massaged for 2 to 3 minutes, each day for 12 days beginning on day 1 of the lactation induction protocol. The length and circumference of the teat of each animal was measured on days 0,7 and 14 and the volume of each teat was estimated using its radius (r) and length (h) according to volume $=\pi r^{2} h$. Animals induced into lactation were milked 2 times per day, once at 6 am and then again at $4 \mathrm{pm}$. Daily milk production was recorded for 22 weeks. Three cycles of experiments were completed, each for about 6 to 7 months (22 weeks of monitoring milk production), using 3 sets of different animals from two locations, the University Field Station (two cycles) and the Aripo Field Station (one cycle).

\subsection{Cost Benefit Analysis}

The economic benefit of using a lactation induction (LI) protocol was determined using a partial budget analysis. The milk produced was sold to Nestle Trinidad limited The total revenue, obtained, for the proportion of animals that were successfully induced to lactate, was calculated by taking into consideration, the average total (for the 22 weeks period) milk yield per cow induced, the number of weeks of production, and the average price. It was assumed that no revenue would have been obtained from these animals otherwise since they were all dry and open.

The total revenue was reduced by the total cost of treating all animals with the hormone protocol and the additional feed costs from the protein concentrate. The forage consumption by dry and lactating animals was assumed to be the same. Therefore, no additional cost was attributed to forage and the reduction in revenue for this was placed at \$TT 0.00 . The net profit per animal was estimated as revenue minus treatment and feed costs.

\subsection{Net Present Value Calculations}

Net Present Values (NPV) were calculated for 4 scenarios which compared culling and replacing a cow with retaining animals in the herd and inducing lactation through a hormonal protocol. The calculations assume an "investment" period of 22 weeks, the duration of the milk production after Lactation Induction. In the different scenarios, the costs at the beginning of the period are estimated as either 1) the costs of the hormonal treatment and extra protein supplement given to animals during the LI protocol or 2) the net cost/profit of selling an animal and acquiring a replacement. During the "investment" period, weekly net cash flows are estimated as the average profit from milk sales (of the average weekly milk yield) minus the costs of feeding the animal. Note animals in which lactation had been induced continued to get a daily protein supplement to their normal feed, which is included in the costs. At the end of the investment period, in the $23^{\text {rd }}$ week of each scenario, the ani- 
mal is hypothetically "sold" and the sale price is included in the calculations, which are given by Equation (1).

$$
N P V=\sum_{i=1}^{n} \frac{(\text { NetCashFlow })^{i}}{(1+D R)^{i}}
$$

$D R$ is the discount rate for the period " $i$ ", written as a decimal. The period " $i$ " is 1 to 22 weeks.

\subsection{Statistical Analysis}

The experimental data obtained in this study were analyzed statistically using the Statistical Package for the Social Sciences, SPSS, V.17 and the Statistical Analysis System $\left(\mathrm{SAS}^{\circledR}\right)$ software [12].

\section{Effects of Mammary Stimulation, Parity, Location, and Time on Milk Production}

A General Linear Model (GLM) Repeated Measures Analysis of Variance (ANOVA) analysis was used to determine the impact on weekly milk production (the dependent variable) of the independent factors of Parity (cow/heifer), Treatment (stimulation/non-stimulation), and Location (one of three cycles at two farms from which the animals in the study were drawn) and of the repeated measure Time (22 weeks). Both Multivariate and Uni-variate tests are explored to assess the impact of Time, as well as those of the interactions (two-way, three-way, and four-way) between each of the main factors and Time (within subject effects) on each animal's weekly milk production. The between subject effects for Parity, Treatment, Location and interactions between them (three two-way and one three-way interaction) are tested using Uni-variate measures. The type IV method in the GLM procedure is used because the cell frequencies, for the layout of Parity, Treatment, and Location, as well as for the interaction effects, are unbalanced.

Chi Square tests were used to look at any possible correlations between the proportions of animals induced into lactation (yielding greater than $7 \mathrm{~kg}$ of milk/day at peak milk production) and Treatment or Parity. A twoway ANOVA test (for the two factors Parity and Treatment) was used to determine the main and interaction effects on volume changes of mammary glands. Independent Groups t tests were used to check the significance of any differences between the stimulated and unstimulated animals with regard to the persistency of milk production (number of weeks in milk production $>7 \mathrm{~kg}$ of milk/day), peak milk production, and the time from induction to peak milk production.

The effect of mammary dimensions on milk production was determined by grouping cows and heifers with high and low volume changes (approximately upper and lower 50 percentile) and analyzing (via two independent groups $t$ tests) the effects of these groups on milk production.

\section{RESULTS}

Three cycles of experiments were completed, each for about 6 to 7 months (22 weeks of monitoring milk production), using 3 sets of different animals from two locations, the University Field Station (two cycles) and the Aripo Field Station (one cycle). Although animals were milked twice a day for the entire period, the quantities collected are combined into units of weekly production or even average weekly production for the purposes of analysis.

\subsection{Success Rates of Lactation Induction}

The mean success rates for lactation induction were $71 \%$ and $85 \%$ for cows and heifers respectively. The rates for successful lactation were not affected significantly (at $\alpha$ $=0.05$ ) by Mammary Stimulation Treatment, by Parity or by the interaction between the absence/presence of stimulation and whether cows or heifers were being treated.

\subsection{Factors Impacting Weekly Milk Production}

The weekly milk production was $78.2 \pm 5.1 \mathrm{~kg}$. Milk production varied significantly $(\mathrm{p}<0.0001)$ from week to week. The milk yield, averaged over all animals, increased continuously between weeks $1-4$, remained elevated until peaking in week 9 then declined throughout the remainder of the study (Figure 2). Average overall milk yield remained above the baseline (week one) values until week 21 of lactation.

The weekly milk production values were not affected significantly (at $\alpha=0.05$ ) by the Treatment ("Regimen") given to the animal. Milk production was affected, however, by which location/cycle ("Farm") the animals were drawn from $(\mathrm{p}=0.0002)$ and by Parity or "Status" $(\mathrm{p}=$ 0.04).

From the Multivariate tests, several interactions are significant. These include the two way interactions Week $\times$ Farm $(\mathrm{p}=0.000)$, Week $\times$ Treatment (stimulation/no stimulation) $-p=0.021$. These indicate that the week to week pattern varies with the location/cycle from which the animal is drawn and varies also with whether the animal's teats are being stimulated or not. The pattern for the animals from the Aripo facility is quite distinct (Figure 3).

Their milk production remained at peak value even until the $22^{\text {nd }}$ week. It would be too speculative at this point to offer an explanation for this, in the absence of more research into factors not researched in this study. The significant "Week $\times$ Stimulation Treatment" interaction is exhibited graphically by the fact that the gap between the milk yields of stimulated and un-stimulated animals changed with Time, being initially (first 12 to 13 
AVERAGE MILK YIELD

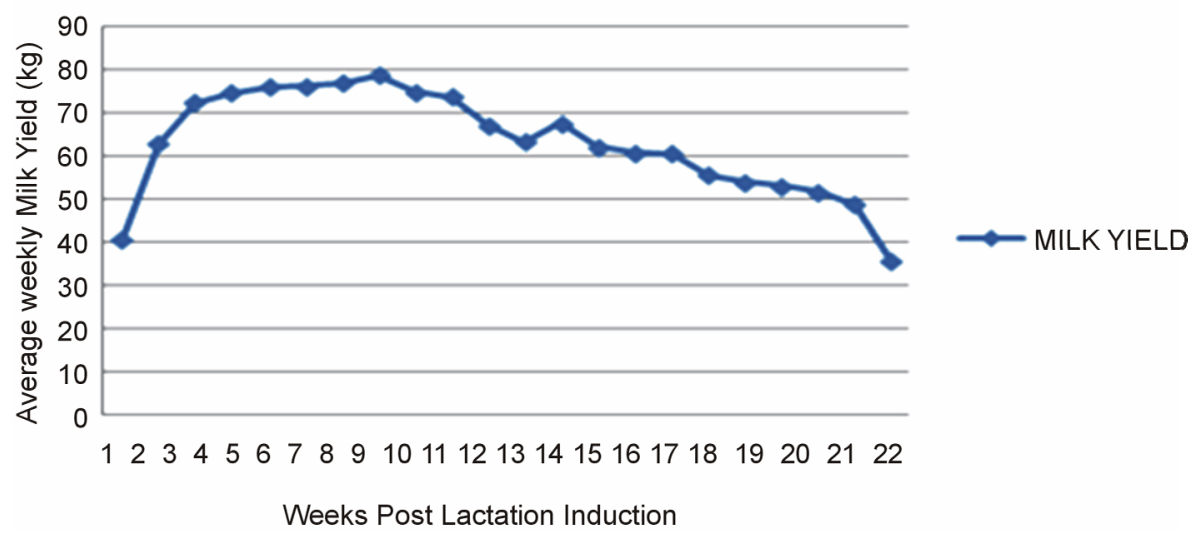

Figure 2. Average weekly milk yields for all cows and heifers induced into lactation.

Impact of Location (Farm) on Weekly Milk Yields

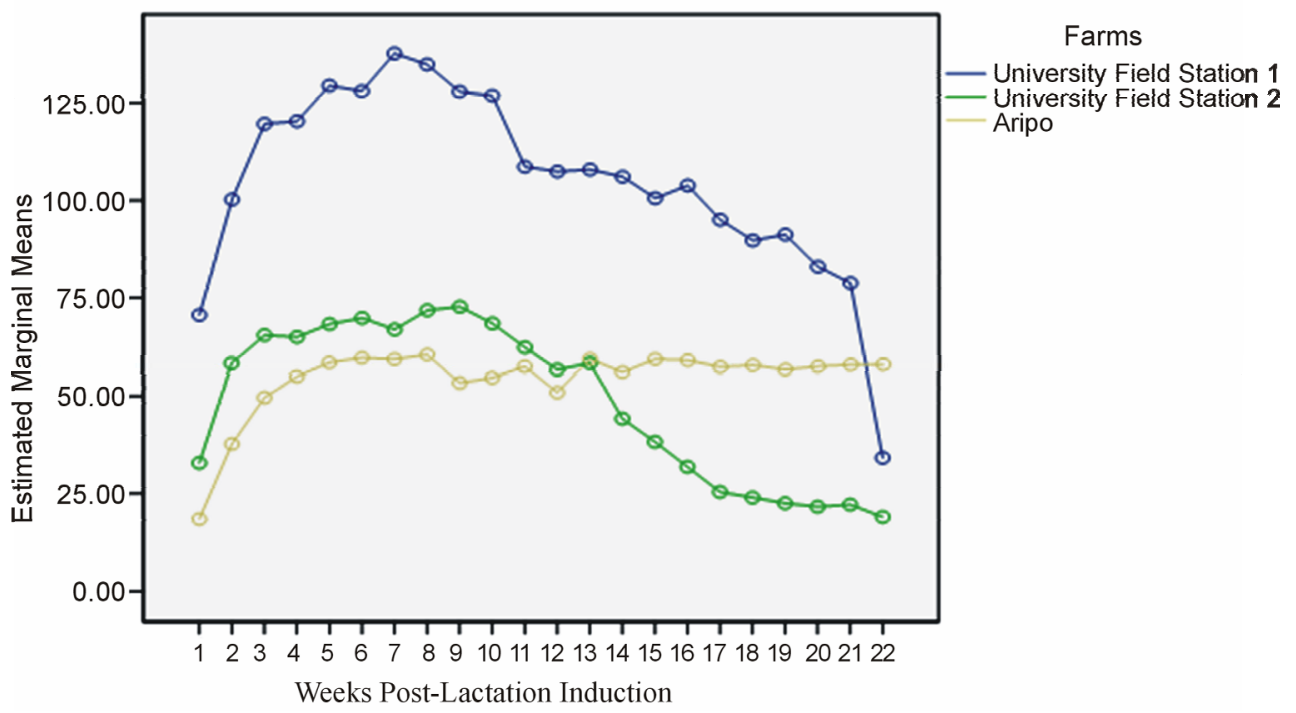

Figure 3. Impact of sample location (farm) on average weekly milk yields - all animals.

weeks) relatively large before tapering off to zero by the $22^{\text {nd }}$ week . This is seen with both heifers (Figure 4) and cows (Figure 5).

The Week $\times$ Parity interaction did not affect significantly (at $\alpha=0.05$ ) the milk yield. Graphically we can note that milk production from cows, both stimulated and un-stimulated, remained elevated above week 1 levels till the 22nd week (Figure 5) but for heifers, as seen in Figure 4, yields reverted to their week one levels after week 16. This resulted in significantly $(p<0.05)$ higher milk yields in cows than in heifers from weeks 8 to 22 . Still, when the 22 week period is tested the Week $\times$ Parity interaction is not significant. This is probably due to a large within group (error) variance when the entire 22 week period is considered.

The Week $\times$ Parity $\times$ Stimulation Treatment 3-way interaction effect is significant $(p=0.029)$. This can be deduced graphically by Figure 6 where all the plots are seen to cross each other or from the combined information provided by Figures 4 and 5. Milk production from week to week was similar in treated (HS) and un-treated (HNS) heifers across all weeks (Figure 4), but the week - treatment pattern of milk production was different for treated (CS) and un-treated cows (CNS)_Figure 5. This is a physical manifestation of the significant 3-way interaction effect because the two-way interaction of Time $\times$ Stimulation is different for the two Parity levels, cow or heifer.

The other 3-way interactions are either not significant for any of the 4 Multivariate tests (Week $\times$ Farm $\times$ Parity) or not significant for at least one of the 4 tests (Week $\times$ Farm $\times$ Treatment). This may be because the strong Week $\times$ Farm 2-way interaction, common to both of these is not altered when it is observed under different 


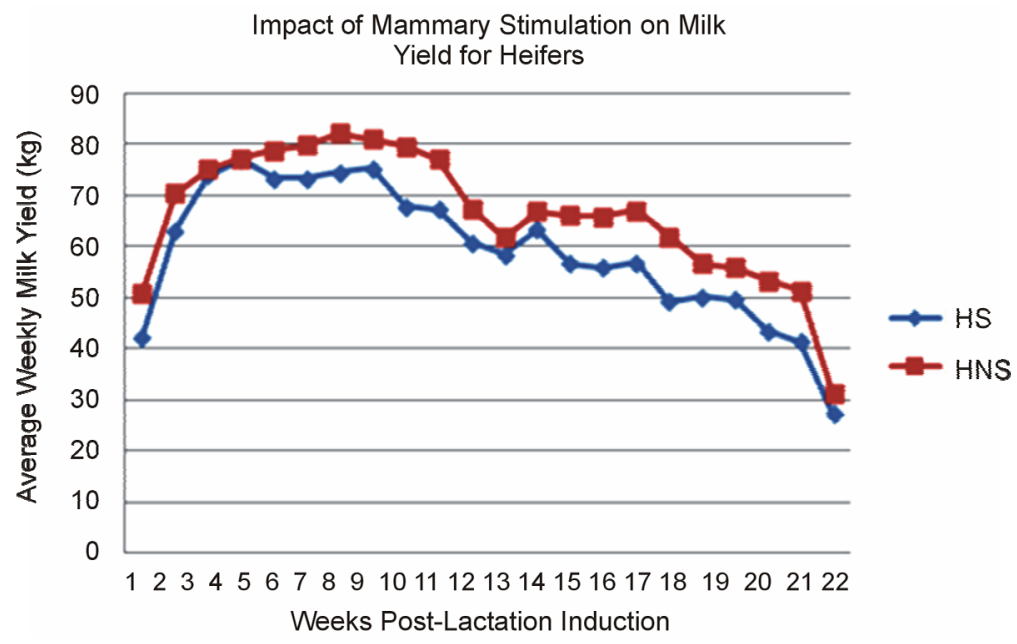

Figure 4. Impact of mammary stimulation on the milk yields of induced heifers (HS and HNS represent stimulated and non-stimulated heifers respectively).

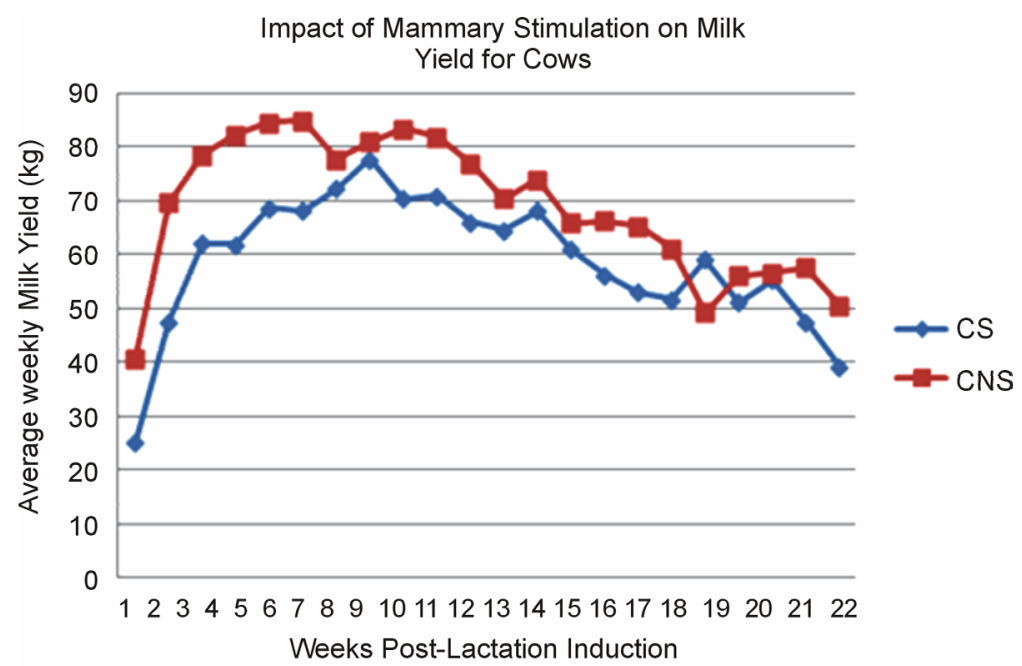

Figure 5. Impact of mammary stimulation on the milk yields of induced cows.

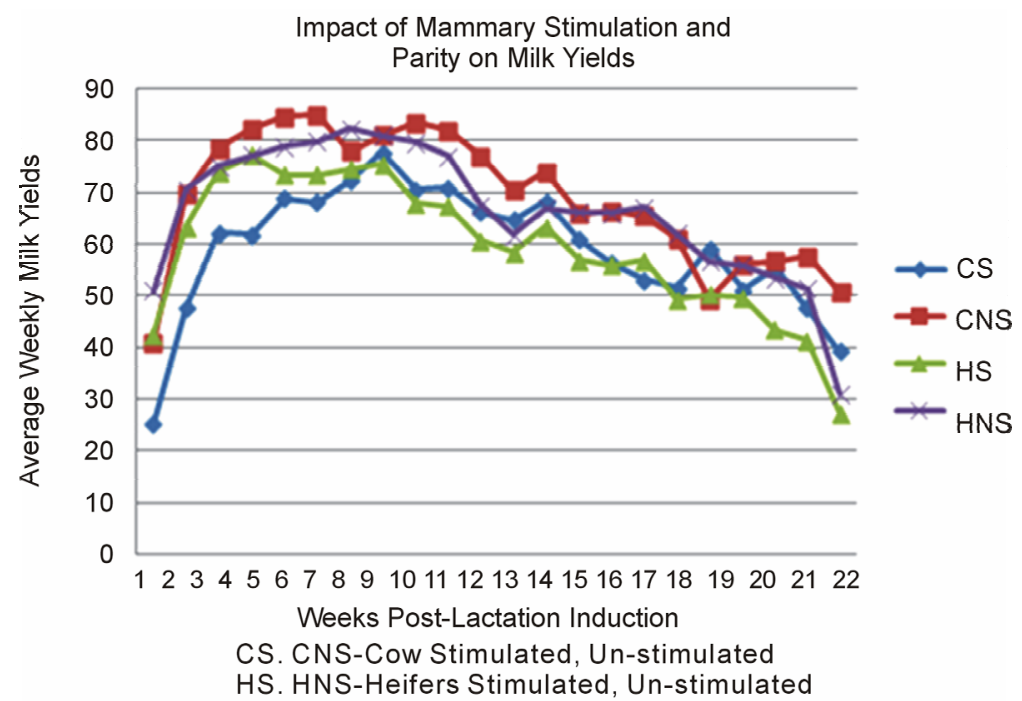

Figure 6. Impact of mammary stimulation and parity on weekly milk yield. 
conditions of Parity or of Treatment.

\subsection{Peak and Persistency of Milk Production}

Peak milk production $(101.6 \pm 5.9)$ was not affected significantly (at $\alpha=0.05$ ) by Mammary Stimulation or by Parity. The average time over all animals from lactation induction to peak milk production was $9.1 \pm 2.2$ weeks. Heifers (at $8.2 \pm 1.0$ weeks) tended to reach peak milk production slightly earlier, but not significantly so $(\mathrm{p}=0.1)$, than cows $(10.7 \pm 1.3$ weeks $)$.

The persistency of milk production was $16.9 \pm 2.4$ weeks and was not affected significantly (at $\alpha=0.05$ ) by Mammary Stimulation or by Parity

\subsection{Mammary Dimensions}

Teat volumes, at the start of the treatment (day 1) and at day 7 are detailed in Table 1 for cows and heifers which had been randomly assigned to both the treatment and control groups. In spite of random assignment, the average initial teat volumes for cows in the two groups were not equivalent. The overall teat volume at the start (day 1) of mammary stimulation was $15.5 \pm 8 \mathrm{~mm}^{3}$. However, the average teat volume of all cows $(25 \pm 2.4$ $\left.\mathrm{mm}^{3}\right)$ was significantly larger $(\mathrm{p}<0.001)$ than the average for all heifers $\left(10.4 \pm 1.7 \mathrm{~mm}^{3}\right)$.

Further, the teats of cows (average volume $=31.2 \mathrm{~mm}^{3}$ ) assigned to the control group (no stimulation) were significantly higher $(p=0.04)$ than those in the group assigned to be given mammary stimulation (average volume $=18.8 \mathrm{~mm}^{3}$ ). In heifers, there was no appreciable difference initially in the teat volumes of the animals in the treatment (stimulation) or control (no stimulation) groups. This disparity between the initial teat volumes of cows and heifers in the stimulated and un-stimulated groups is confirmed by the just significant $(p=0.05)$ Parity $\times$ Treatment interaction effect seen for the day 1 data (Table 1). Note, however, this result is only a reflec- tion of the group assignment and not of the impact of any factor. It shows simply that at the beginning of the experiment, the groups were not equivalent.

These same patterns (significant differences between untreated and treated cows but not among heifers) are repeated for the day 7 data. The teat volumes for all animals increased from day 1 to day 7 . However, the largest percentage changes were in the groups of un-stimulated cows $(74.3 \%)$ and of stimulated heifers (68.3\%)-Table 1.

From the statistical analysis of the impact of teat volumes on milk production, animals with larger teat volumes gave higher mean milk yields on both day $1(\mathrm{p}=$ $0.09)$ and day $7(\mathrm{p}=0.01)$. The weekly milk production for induced animals with high teat volumes (un-stimulated) was $87.5 \pm 6.1$ (day 1) and $87.6 \pm 6.5$ (day 7). For those animals with low teat volumes, the weekly milk yields were $71.9 \pm 6.7$ (day 1 ) and $73.7 \pm 6.7 \mathrm{~kg}$ (day 7 ).

\subsection{Economic Analysis of Lactation Induction}

The additional revenue derived from lactation induction of all animals over the 22 weeks was $\$ 208,130.55$ TT or $\$ 4428.31$ TT per animal treated (Table 2). The overall additional cost incurred was estimated to be $\$ 104,434.00$ TT or $\$ 2222.00$ TT per animal treated. The net profit derived from lactation induction was $\$ 2206.31$ TT per animal treated (Table 2).

In addition to the above approach the Net Present Values (NPV) of animals, given three possible scenarios, were calculated. These include the situations where:

1) a cow, instead of being culled, is induced into lactation, after which milk is collected for 22 weeks. In the $23^{\text {rd }}$ week, the animal is sold;

2) a heifer is induced into lactation, after which milk is collected for 22 weeks before the animal is sold in the $23^{\text {rd }}$ week; and

3) a cow is sold and a new replacement cow is purchased at the very beginning of the period. The replace-

Table 1. Effect of mammary stimulation and parity on the teat volumes of animals treated with an LI protocol.

\begin{tabular}{|c|c|c|c|c|c|c|c|}
\hline & \multicolumn{4}{|c|}{ Teat Volumes ( mean \pm standard deviation) } & \multirow{2}{*}{\multicolumn{3}{|c|}{ p-Values }} \\
\hline & \multicolumn{2}{|c|}{ Cow } & \multicolumn{2}{|c|}{ Heifer } & & & \\
\hline & Un-stimulated & Stimulated & Un-stimulated & Stimulated & Parity & Treatment & Parity $\times$ Treatment \\
\hline $\begin{array}{l}\text { Vol. day } 1 \\
\quad\left(\mathrm{~mm}^{3}\right)\end{array}$ & $31.2 \pm 3.3$ & $18.8 \pm 3.6$ & $10.7 \pm 2.4$ & $10.1 \pm 2.4$ & 0.0001 & 0.04 & 0.05 \\
\hline $\begin{array}{l}\text { Vol. day } 7 \\
\left(\mathrm{~mm}^{3}\right)\end{array}$ & $54.4 \pm 8.3$ & $29.9 \pm 9.1$ & $15.7 \pm 6.1$ & $17 \pm 6.1$ & 0.002 & 0.1 & 0.09 \\
\hline $\begin{array}{l}\text { Vol. change } \\
\qquad\left(\mathrm{mm}^{3}\right)\end{array}$ & $23.2 \pm 5.9$ & $11.1 \pm 6.5$ & $5 \pm 4.4$ & $6.9 \pm 4.4$ & 0.04 & NS & NS \\
\hline $\begin{array}{c}\% \\
\text { change }\end{array}$ & 74.3 & 59 & 46.7 & 68.3 & & & \\
\hline
\end{tabular}


Table 2. Economic analysis of the impact of using the LI protocol.

\begin{tabular}{|c|c|}
\hline PRELIMINARY DETAILS & INFORMATION \\
\hline Number of Animals & 47 \\
\hline Average Total Milk Yield per Cow Induced & $78.2 \mathrm{~kg}$ \\
\hline Duration of Milk Production & 22 Weeks \\
\hline Average Price of milk & $\$ 3.30 / \mathrm{kg}$ \\
\hline Daily Consumption of Concentrate per Animal & $5 \mathrm{~kg}$ \\
\hline Duration of Feeding & 177 days $=23$ days of $L I+22$ weeks (154 days) \\
\hline Price of Concentrate & $\$ 2.20 / \mathrm{kg}$ \\
\hline Cost per animal of LI PROTOCOL & $\$ 275$ \\
\hline Success rate of LI protocol (\%) & 78 \\
\hline ACTIVITY & COSTS \\
\hline Administration of LI PROTOCOL & TT $\$ 275 /$ animal $\times 47$ animals $=$ TT $\$ \mathbf{1 2 , 9 2 5}$ \\
\hline Feeding with concentrate & $5 \mathrm{~kg} /$ day $\times 177$ days $\times$ TT $\$ 2.20 / \mathrm{kg} \times 47$ animals $=$ TT $\$ \mathbf{9 1 , 5 0 9}$ \\
\hline Additional Forage & \$0 - same for dry and lactating animals \\
\hline Total Costs & $\$ 12,925+\$ 91,509=\$ 104,434$ \\
\hline PRODUCT & REVENUE \\
\hline Milk Sales & $78.2 \mathrm{~kg} /$ week $\times 22$ weeks $\times$ TT $\$ 3.30 / \mathrm{kg}) \times 47$ animals $\times$ the success rate $(78 \%)$ of the LI \\
\hline \multirow[t]{2}{*}{ Total Revenue } & $\$ 266,834.04 \times 0.78=\mathbf{\$ 2 0 8}, \mathbf{1 3 0 . 5 5}$ \\
\hline & $\mathrm{NUE}=\$ 208,130.55-\$ 104,434=\$ 103,696.55$ \\
\hline
\end{tabular}

ment cow gets pregnant immediately (or never) and is sold in the $23^{\text {rd }}$ week.

Induced animals incur a cost from the Lactation Induction Protocol treatment during which they are given both hormones and a protein concentrate. Their usual feed is enhanced with protein concentrate throughout the milking period. They earn money weekly, however, from the milk that is sold. In Table 3 are summarized the NPV amounts for the scenarios above.

\section{DISCUSSION}

\subsection{Lactation Induction Success Rate}

Artificial induction of lactation with the current protocol yielded an average overall success rate of $78 \%$. The success rates achieved in the current study are similar to those reported in previous studies $[13,14]$. The success rate for heifers $(85 \%)$ was less than that $(97 \%)$ reported previously [15]. The success rate for cows (71\%) was somewhat lower than the $90 \%$ rate reported by Jewel [14]. The lower success rates in this study may be related to the more restrictive requirement used here for an animal to be considered induced.

In the present study lactation was considered to have been induced in an animal if the peak milk production was greater than $7 \mathrm{~kg}$ /day, which is $33 \%-50 \%$ of the peak daily milk yield for un-treated cattle in Trinidad. Conversely, Jewel [14], among others, used a relatively less conservative milk yield of 5 and $9 \mathrm{~kg} /$ day for Jersey
Table 3. NPV values for induced and culled animals.

\begin{tabular}{cc}
\hline Scenario & NPV (TT\$) \\
\hline Lactation Induced Cow & 7397.70 \\
Lactation Induced Heifer & 5483.14 \\
Replacement Cow ( Pregnant) & 6302.24 \\
Replacement Cow (Not Pregnant) & 3430.40 \\
\hline
\end{tabular}

and Holstein cattle respectively, representing only $20 \%$ of the peak yield in un-treated, naturally-induced lactations in cattle in the regions under study.

\subsection{Weekly and Peak Milk Yields}

The mean and peak weekly milk yields of induced animals were $78 \mathrm{~kg}$ and $102 \mathrm{~kg}$ or approximately 11 and $15 \mathrm{~kg}$ /day respectively. Mammary simulation did not affect overall milk yields (the main effect is not significant) but tended to maintain milk yields above basal (week 1) levels for a significantly longer period of time (The Time $\times$ Stimulation interaction effect is significant with $\mathrm{p}=0.021)$. Given the teat volume results, detailed in Table 1, it is possible that the mammary gland development due to stimulation may have been inadequate and somewhat delayed resulting in only small impacts on milk production later in lactation.

The daily and peak milk yields of induced animals were similar to or greater than the average daily or peak milk yields reported for cattle in several tropical coun- 
tries [16-18]. However, in those studies milk yield of induced cows and heifers was only $48 \%-68 \%$ of the yield of comparable animals in the same herd. The relatively better production $(11 \mathrm{~kg}$ and $15 \mathrm{~kg}$ daily for average and peak yields) of induced animals in this study, compared to the expected values (10 kg daily) for animals in Trinidad \& Tobago, might be related to the improved management received by these animals relative to herd mates. Additionally, it should be noted that the lactation induction procedure used in this study and others, while adequate to support low levels of milk production, may not be sufficient to induce all the changes associated with pregnancy and to support the high levels of milk production observed in dairy cows in Temperate regions, where milk yields are much higher usually than in the Tropics.

In some previous lactation-induction studies, peak milk yields were reached 7 to 8 weeks into lactation [10]; [19]. In those studies the peak milk yield for cows induced into lactation did not occur until 30 to 60 days after milking was initiated. However, Smith \& Schanbacher [10] reported a rapid daily increase in milk yield during the first 10 to 12 days following induction of lactation with an estrogen/progesterone protocol. Those results were consistent with the findings from this study, in which rapid increases were also noticed in the first two weeks. The time to peak milk production for unstimulated cows was $8.7 \pm 1.8$ weeks and $12.7 \pm 1.8$ weeks for the stimulated animals. Heifers in the stimulated group reached peak milk production earlier $(7.8 \pm$ 1.3 weeks) whereas those in the un-stimulated group reached peak milk production in $8.4 \pm 1.4$ weeks. In all cases, though, that initial rapid jump in milk yield resulted in values that were very close to peak by the 3 or $4^{\text {th }}$ week-Figure 2.

\subsection{Mammary Dimensions}

The mean teat volume at the start of mammary stimulation (day 1) was $15.5 \pm 8 \mathrm{~mm}^{3}$ and was significantly higher in cows than heifers $\left(10.4 \pm 1.7 \mathrm{~mm}^{3}\right)$. Volumes were also higher in the cows assigned to the control group (no stimulation) than in those assigned to be stimulated. There was very little difference in the mean teat volumes at day 1 for heifers in the treatment (stimulation) and in the control groups (Table 1).

The mean teat volumes for animals in all groups grew by day 7 . However, the largest teat volume changes occurred in the group of un-stimulated cows (74.3\%) and in the group of stimulated heifers $(68.3 \%)$. The pattern observed for cows at day 1 persisted up to day 7 in that the mean teat volume in stimulated cows lagged even further behind that in the un-stimulated group (only 59\% teat volume increase for the former compared to $74.3 \%$ for the latter). In the case of heifers, the difference in mean teat volumes by day 7 , between treated (stimulated) and control (no stimulation) groups, was marked, although not statistically significant, probably because of the within group variances. The two groups had equivalent mean teat volumes initially but the change by day 7 for the stimulated group of heifers was $20 \%$ larger than that for the un-stimulated group $(68.3 \%$ as opposed to 46.7\%).

The positive impact of Mammary Stimulation on the teat volume in heifers (as opposed to the smaller impact with cows) may possibly be due to the contribution of Growth Factors. The results in this study corroborate the findings by Massague \& Chen [20]. These researchers associated the Transforming Growth Factor-beta (TGF- $\beta$ ) with a growth factor which is expressed during bovine mammary development and which may prove to be especially important during a critical period of mammary development in heifers. The teat stimulation employed in this study may have caused the Transforming Growth Factors in heifers to be expressed, resulting in enhanced mammary development.

Further, as stated by Purup et al. [21], pre-pubertal mammary development is controlled through the combined actions of Growth Hormone (GH), Estrogen (E) and locally derived Growth Factors such as insulin-like Growth Factor (IGF-I), whereas allometric growth in heifers is dependent on ovarian secretions. Stimulation may have had no effect on cows because according to Topper \& Freeman [22], the majority of bovine mammary development occurs during pregnancy when mammogenic hormones, such as Growth Hormone, Estrogen and Progesterone, stimulate proliferation of mammary epithelial cells and subsequent formation of mature alveoli. Therefore, in this study there should have been little mammary development for the animals already exposed to a pregnancy.

\subsection{Impact of Teat Volumes on Milk Production}

Cows in both groups - treatment and control-showed initial mean teat volumes that were larger than those for heifers. This is expected because heifers should not have complete involution of the mammary glands, resulting in the smaller teat volumes observed. As stated before, by day 7 the mean weekly milk production for animals with high teat volumes $(87.6 \mathrm{~kg})$ was significantly $(\mathrm{p}=0.01)$ different from the mean $(73.7 \mathrm{~kg})$ for those with lower teat volumes. On day 1 , at the start of treatment, the mean milk yields for the two groups were different $(87.5$ $\mathrm{kg}$ and $71.9 \mathrm{~kg}$ for animals with high and low teat volumes respectively) but that difference was not found to be significant at the $5 \%$ critical level $(p=0.09)$. (This is probably due to larger "within group" variances in teat volumes on day 1 as opposed to day 7 which would have 
led to a larger pooled standard error and so a smaller test statistic). These findings were similar to those obtained from studies done with Awassi sheep [23]. According to those authors, udder measurements from one study to the next and between flocks/herds vary considerably, partly depending on when the measurements were taken, relative to the milking period, and on the time of milking.

In this study, mammary dimensions were taken on day 1 , day 7 and day 14 and the results obtained were comparable to those of McKusick et al. [24], who assessed a US population of East Friesan sheep. They found that ewes with greater udder circumferences and udder lengths had greater commercial milk yields. This study showed that there were variations in mammary dimensions among the heifers and cows which resulted in an increase in milk produced from those animals having greater teat circumference and length.

For both cows and heifers, the stimulated animals gave lower yields than those whose teats were un-stimulated but with cows the effect is far more marked (Figures 4 and 5). The un-stimulated cows also had larger teat volumes than those which were not stimulated. The heifers showed no significant difference in teat volumes but the un-stimulated animals still appeared to have a marginally better milk yield, although showing a smaller effect and for fewer weeks in the 22-week period than that seen for cows. (This difference in the stimulation/non-stimulation pattern over time seen with cows and heifers was outlined before when it was pointed out that the 3-way interaction of Parity $\times$ Treatment $\times$ Time was significant).

These results were in synch with those of other studies [25-28].

It has been suggested that the morphology traits such as udder circumference, udder shape, teat length and teat width are moderately heritable and are significantly correlated with milk yield [28-32].

\subsection{Economics of Lactation Induction}

The average daily milk production for dairy cattle in Trinidad, Jamaica and other tropical countries is approximately $10 \mathrm{~kg} / \mathrm{day}$. Therefore, the mean weekly milk production of $78 \mathrm{~kg}$ obtained by lactation induced animals in this study is higher than the average milk production obtained naturally and considerably more than would be obtained for heifers and cows that otherwise would not be lactating or would be producing only very small quantities of milk.

The comparatively high level of milk production and the high success rate of the lactation induction protocol used in this study contributed to the high profit per animal obtained. Magliaro et al. [8] found a significantly higher ( $\$ 500.00$ US) NPV for induced cows than that for first-lactation cows. Kensinger [7] found it more profitable to induce lactation in non-breeder cows than to pur- chase replacement heifers or to cull non-lactating cows. However, Macrina et al. [15] found no economic benefit in using lactation induction in heifers. The high fertility of dairy heifers in temperate regions in this last study might have led to the estimation of no beneficial effects of lactation induction.

In this study, the NPV values calculated support the conclusions of Magliaro et al. [8]. A cow induced into lactation should earn $\$ 1095$ TT more profit than a replacement cow, if it becomes pregnant, and \$3967 TT more than one that does not $(\$ 1 \mathrm{US}=\$ 6.40 \mathrm{TT})$. Even an induced heifer can be \$2053 TT more profitable than a replacement cow that remains open (Table 3 ).

\section{CONCLUSIONS}

The results from this study suggest that induction of lactation is possible in dairy cattle and heifers in the Tropics if commercial hormones are readily available. The average success rate of $78 \%$, while a bit lower than those observed in other studies, should be considered very good, given the more stringent requirements used for "success" ( $>7 \mathrm{~kg} /$ day , where the average milk yield is $10 \mathrm{~kg}$ /day for cattle in Trinidad \& Tobago). Milk yields from the induced animals rose quickly in the first 2 to 3 weeks, rising almost to peak which was achieved between 8 and 13 weeks for most animals in the study.

The daily mean $(11 \mathrm{~kg})$ and peak $(15 \mathrm{~kg})$ yields for the induced animals in this study compared very favourably with the daily average of $10 \mathrm{~kg}$ for untreated cattle in the region. Persistency, which averaged 16.9 weeks \pm 2.4 weeks, was excellent, lasting till almost 21 weeks for many animals and, in others (especially those from the Aripo facility), for all 22 weeks.

The average weekly milk yield was affected significantly (at $\alpha=0.05$ ) by "Parity" (cows yielded more than heifers) and by "Farm" (the location-Aripo or University Field Station in $1^{\text {st }}$ or $2^{\text {nd }}$ cycle-from which the animals were drawn). It was not affected by "Stimulation". This last result though belies some other interesting results. Although the main effect of "Stimulation" was not significant, other results suggest that Stimulation may play a part. Teat volumes were found, as in other studies, to be correlated with milk yield. Heifers showed the better teat volume response to stimulation.

Stimulation may have caused the expression of Transforming Growth Factors in heifers, promoting enhanced teat volumes, and in the process, larger milk yields. So stimulation does have an indirect impact, the importance of which may have been masked (main effect not significant) by the initial (day 1) within groups variance in teat volumes in the stimulated and un-stimulated groups. The two-way interactions with Time are worth noting. The significant "Week $\times$ Stimulation" interaction suggests that the effects of stimulation vary with time, as 
would be expected if stimulation is operating through its impact on teat volumes for heifers, in particular. The significant Week $\times$ Farm interaction will need more study before definitive conclusions can be drawn.

Economic analysis of the results suggests, from the straightforward approach of costs versus revenue, that a profit of \$2206.31 TT per animal is generated by hormonal Lactation Induction. NPV analysis for different scenarios estimates that cows exposed to a LI protocol can generate from $\$ 1195$ TT to $\$ 3967$ TT more profit than a replacement cow, depending on whether the replacement for the culled animal becomes pregnant or not.

The Lactation Induction technique can be used as a management tool to assist farmers in re-introducing culled animals with good genetics for milk production back into the productive herd without any losses incurred. It provides additional opportunities at rebreeding. With this technology, there is a potential to increase income by reducing the number of replacement heifers and the retention in the herd of cows of high genetic merit.

\section{ACKNOWLEDGEMENT}

The authors thank the farms staff of the Aripo Livestock Station and the University of the West Indies Field Station, Trinidad West-Indies.

\section{REFERENCES}

[1] Livestock in a Balance (2009) Food and Agricultural Organization (FAO).

[2] Allaire, F.R., Sterwerf, H.E. and Ludwick, T.M. (1977) Variations in removal reasons and culling rates with age for dairy females. Dairy Science, 60, 254-267. http://dx.doi.org/10.3168/jds.S0022-0302(77)83862-9

[3] Nahms, N.A. (1996) Dairy management practices. USDA, Washington, DC, 18-21.

[4] Loeffler, S.H., de Vries, M.J. and Schukken, Y.H. (1999) The effects of time of disease occurence, milk yield and body condition on fertlity of dairy cows. Dairy Science, 82, 2589-2604. http://dx.doi.org/10.3168/jds.S0022-0302(99)75514-1

[5] Heinrichs, J. (1996) The importance of heifer raising to a profitable dairy farm. Calf, Heifer and Dairy Profitability National Conference, NRAES, 7425.

[6] Magliaro, A.L., Ford, S.A., O’Connor, L., Muller, L.D., Graboski, R. and Kensinger, R.S. (1999) Induced lactation of nonpregnant cows or use of replacement heifers: A profitability comparison. Dairy Science, 82, 19.

[7] Kensinger, R.S. (2000) Induced lactation physiology, perception, profitability and propriety. Dairy Science, 83, 23.

[8] Magliaro, A.L., Kensinger, R.S., Ford, S.A., O'Connor, M.L., Muller, L.D. and Graboski, R. (2004) Induced lactation in Nonpregnant Cows: Profitability and Response to Bovine Somatotropin. Dairy Science, 87, 3290-3297. http://dx.doi.org/10.3168/jds.S0022-0302(04)73465-7

[9] Cowie, A.T., Cox, C.P., Folley, S.J., Hosking, Z.D., Naito,
M. and Tindal, J.S. (1965) The effects of the duration of treatments with estrogen and progesterone on the hormonal induction of mammary growth and lactation in the goat. Endocrinology, 32, 129-139. http://dx.doi.org/10.1677/joe.0.0320129

[10] Smith, K.L. and Schanbacher, F.L. (1973) Hormone induced lactation in the bovine. I lactational performance following injections of 17 -estradiol and progesterone. Dairy Science, 56, 738. http://dx.doi.org/10.3168/jds.S0022-0302(73)85243-9

[11] Salama, A.K., Caja, G., Albanell, E., Carne, S., Casals, R. and Such, X. (2007) Mammogenesis and induced lactation with or without Reserpine in nulliparous dairy goats. Dairy Science, 90, 3751-3757. http://dx.doi.org/10.3168/jds.2007-0039

[12] Body Condition Scoring in Cattle (2000) Department for Environment, Food and Rural Affairs (DEFRA).

[13] Collier, R.J., Bauman, D.E. and Hays, R.L. (1977) Effects of reserpine on milk production and serum prolactin of cows hormonally induced into lactation. Dairy Science, 60, 896. http://dx.doi.org/10.3168/jds.S0022-0302(77)83960-X

[14] Jewel, T. (2000) Artificial induction of lactation in nonbreeder dairy cows. Unpublished Master of Science dissertation, Virginia Polytechnic Institute and State University, Blacksburg.

[15] Macrina, A.L., Tozer, P.R. and Kensinger, R.S. (2011) Induced lactation in pubertal heifers: Efficacy, response to bovine somatotropin and profitability. Dairy Science, 94, 1355-1364. http://dx.doi.org/10.3168/jds.2010-3811

[16] Ageeb, A.G. and Hillers, J.K. (1999) Effect of crossing local Sudanese cattle with British Friesian Bull. Tropical Animal Health and Production, 39, 69-76.

[17] Tambi, E.N. (1991) Dairy production in Cameroon: Growth, development, problems and solutions. World Animal Review, 67, 38-48.

[18] Ackbarally, N. (2009) Milking profits: In a bid to serve the growing demand, both from ordinary citizens and industry, the governement of Mauritius has been offering generous grants and other inducements to encourage cattle herding and milking. African Business Magazine, 362.

[19] Tervit, H.R., Fairclough, R.J., McGowen, L.T., MacKenzie, D.S., Macmillan, K.L. and Peterson, A.J. (1980) Induction of lactation in dry cattle. New Zealand Veterinary Journal, 28, 15 . http://dx.doi.org/10.1080/00480169.1980.34679

[20] Massague, J. and Chen, Y.G. (2000) Controlling TGF-signalling . Genes Development, 14, 627-644.

[21] Purup, S., Sejrsen, K., Foldager, J. and Akers, R.M. (1993) Effect of exogenous bovine growth hormone and ovariectomy on prepubertal mammay growth, serum hormones and acute in vitro proliferative rsponse of mammary explants from holstein heifers. Endocrinology, 139, 19-26. http://dx.doi.org/10.1677/joe.0.1390019

[22] Topper, Y.J. and Freeman, C.S. (1980) Multiple hormone interactions in the developmental biology of the mammary gland. Physiology Review, 60, 1049-1106.

[23] Iniguez, L., Hilali, M., Thomas, D.L. and Jesry, G. (2009) 
Udder measurements and milk production in two Awassi sheep genotypes and their crosses. Dairy Science, 92, 4613-20. http://dx.doi.org/10.3168/jds.2008-1950

[24] McKusick, B.C., Berger, Y.M. and Thomas, D.L. (1999) Preliminary results: Effects of udder morphology on commercial milk production of East Friesian crossbred ewes. University of Wisconsin, Madison.

[25] Gootwine, E., Alef, B. and Gadeesh, S. (1980) Udder conformation and its heritability in the Assaf (Awassi $\times$ East Friesian) cross of dairy sheep in Israel. Annual Genetic Selection Animal, 12, 9-13.

[26] Mavrogenis, A.P., Papachristoforou, C., Lysandrides, P. and Roushias, A. (1988) Environmental and genetic factors affecting udder characters and milk production in Chios sheep. Genetic Selection and Evolution, 20, 477488. http://dx.doi.org/10.1186/1297-9686-20-4-477

[27] Fernandez, G., Baro, J.A., de la Fuente, L.F. and San Primitivo, F. (1997) Genetic parameters for linear udder traits of dairy ewes. Dairy Science, 80, 601-605. http://dx.doi.org/10.3168/jds.S0022-0302(97)75976-9

[28] Carta, A., Sanna, S.R., Ruda, G. and Casu, S. (1999) Genetic aspects of udder morphology in Sarda primiparaous ewes. In: F. Zervas and Barillet, Eds., Milking and Milk
Production of Dairy Sheep and Goats, Wageningen Press, Wageningen, 363-368.

[29] Labussiere, J., Dotchewski, D. and Combaud, J.F. (1981) Caracteristiques morphologiques de la mammelle des brebis Lacaune. Methodologie pour l'obtention des donnees. Relations avec l'aptitude a la traite. Annual Zootechnology, 30, 115-136. http://dx.doi.org/10.1051/animres:19810201

[30] Labussiere, J. (1988) Review of physiological and anatomical factors influencing the milking ability of ewes and the organization of milking. Livestock Production Science, 18, 253-273. http://dx.doi.org/10.1016/0301-6226(88)90035-8

[31] Fernandez, G., Baro, J.A., de la Fuente, L.F. and San Primitivio, F. (1997) Genetic parameters for linear udder traits of dairy ewes. Journal Dairy Science, 80, 601-605. http://dx.doi.org/10.3168/jds.S0022-0302(97)75976-9

[32] Rovai, M., Such, X., Piedrafita, J., Caja, G. and Pujol, M.R. (1999) Evolution of mammary morphology traits during lactation and its relationship with milk yield of Manchega and Lacunae dairy sheep. In: F. Zervas and Barillet, Eds., Milking and Milk Production of Dairy Sheep and Goats, Wageningen Press, Wageningen, 95. 